\title{
Synthesis and characterization of ZnTe nanoparticles
}

\author{
Sujan Dhungana", Bhoj Raj Poudel, \& Surendra K. Gautam
}

Department of Chemistry, Tri-Chandra Multiple Campus, Tribhuvan University, Kathmandu, Nepal

\section{KEYWORDS}

Electron diffraction; semiconductor nanoparticles; transmission electron microscopy; X-ray diffraction; ZnTe

\section{\#CoRrespondence}

Tel: +977 14439850

E-mail:sgautam2055@yahoo.com

\section{Article History}

Received 25 Feburary 2016

Revised 25 May 2016

Accepted 18 June 2016

\section{Academic Editor}

Gan B. Bajracharya

\section{Introduction}

Zinc telluride is a Group II-VI compound semiconductor with a direct band gap of $2.26 \mathrm{eV}$ (Ersching et al. 2010) at room temperature. ZnTe usually had a cubic (sphalerite or zinc blende) crystal structure (Promnopas et al. 2014), but can be also prepared as hexagonal crystals (wurtzite structure) (Dwivedi et al. 2009). It has very potential applications in solid state devices such as solar cell (Promnopas et al. 2014), photodetectors (Liu et al. 2013), light emitting diodes (Shaygan et al. 2014), optoelectronic devices (Mohd et al. 2012), high efficiency multi-junction solar cells (Jioa et al. 2015), terahertz (THz) devices (Loffler et al. 2005) and electronic devices (Lincheneau et al. 2014). All those are dependent on crystal structure and particle size.

Many researchers have been interested to study the nanoparticles for last few decades. Due to their different variety of properties compared to bulk materials. Actually, all kinds of nanoparticle like $\mathrm{Cd}$-chalcogenide have been synthesized by various methods and exhibit size dependent properties (Orii et al. 2007).

Several researchers have employed various techniques for synthesizing ZnTe nanoparticles such as electrodeposition method (Xia et al. 2003), chemical synthesis (Dwevdi et al. 2009), thermal evaporation (Sharma et al. 2013), microwave irradiation (Mohd et al. 2012), sublimation technique (Feng et al. 2013), spray pyrolysis (Kim et al. 2011), microwave plasma (Promnopas et al. 2014), electrical conduction (Hossain et al. 2008), etc.

\section{Materials and Methods}

Zinc-Tellurium nanoparticles were prepared by chemical precipitation method using aqueous medium and ambient condition. All the reactants used were of analytical grades.
ZnTe nanoparticles were synthesized from different sources of zinc salt. Zinc sulphate heptahydrate $\left[\mathrm{ZnSO} 4.7 \mathrm{H}_{2} \mathrm{O}\right]$ (99.99\%), zinc chloride [ $\mathrm{ZnCl} 2]$ (99.5\%) and zinc nitrate hexahydrate [ $\left.\mathrm{Zn}\left(\mathrm{NO}_{3}\right) 2.6 \mathrm{H} 2 \mathrm{O}\right]$ (98\%) were used as zinc source. Tellurium metal powder [Te] (99.99\%) was used as tellurium source. Sodium borohydride $(\mathrm{NaBH} 4)$ was used as reducing agent and deionized water was used in the experiments.

\subsection{Synthesis of $\mathrm{ZnTe}$ nanoparticles}

TThe synthesis approach is very simple and does not require any special set up. A mixture of $\mathrm{Te}$ and $\mathrm{NaBH}_{4}$ (molar ratio; Te:NaBH4 = 1:2.4) was added in $200 \mathrm{ml}$ deionized water and the mixture was stirred in a magnetic stirrer for $20 \mathrm{~min}$ at room temperature. Zinc telluride was prepared from $\mathrm{Zn} 2+$ and NaHTe solution. The 1:1 molar ratio of $\mathrm{Zn}^{2+}: \mathrm{Te}^{2-}$ was mixed and was stirred for half an hr at room temperature in a magnetic stirrer. The temperature was then maintained at $90^{\circ} \mathrm{C}$ for 3 hours. The solution was then filtered and the obtained precipitate was washed with distilled water. It was then finally dried at $45-60^{\circ} \mathrm{C}$. The precipitate obtained was of $\mathrm{ZnTe}$, which was grinded to a powder form. The synthesis process described the following reactions to yield $\mathrm{ZnTe}$ as a final product (Mntungwa et al. 2012).

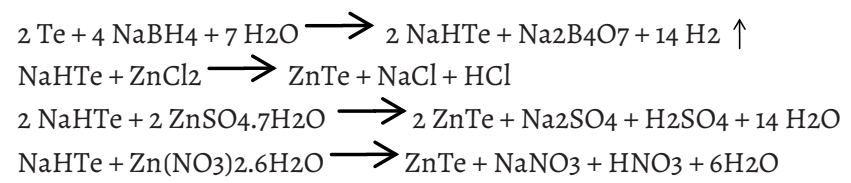

\subsection{Characterization}

As synthesized nanoparticles samples were analyzed using X-ray Diffraction (XRD), Transmission Electron Microscopy 
(TEM) and Selected Area Electron Diffraction (SAED) patterns.

\subsubsection{X-ray Diffraction (XRD)}

XRD pattern provided information about crystalline phase of the nanoparticles as well as particles size. A considerable broadening of diffraction peaks is the characteristic feature of the XRD pattern of nanoparticles. This broadening of the diffraction peak is due to the formation of smaller sized samples.

Average particle size was found from XRD measurement value of full width at half maxima (FWHM) using Debye-Scherrer formula (Dwivedi et al. 2009).

$$
D=\frac{0.94 \lambda}{B \cos \theta}
$$

Where, $D=$ mean diameter of the nanoclusters, $B=$ full width at half maximum $(\mathrm{FWHM}), \lambda=$ wavelength of $\mathrm{CuK} \alpha$ radiation (1.5406 $\AA$ ), and $\Theta=$ Bragg's angle.

The XRD analysis of the synthesized material was carried out by a Rigaku $18 \mathrm{~kW}$ powder X-ray Diffractometer by employing $\mathrm{CuK \alpha}$ radiation of wavelength $(\lambda)$ with anode based graphite monochromator. The diffractometer was operated at $40 \mathrm{kV}$ and $150 \mathrm{~mA}$ of the data recorded in the angular range of $20-120$ degrees geometry with $0.02 \% \mathrm{sec}$ scan rate, which was found to be adequate for characterizing the nanoparticles.

\subsubsection{Microscopic study (TEM/ED)}

TEM is commonly used to characterize the structure and morphology of the nanoparticles. The TEM images of sample were taken by a Tecnai $\mathrm{G}^{2} 20$ electron microscope. For this, the samples were prepared by dropping the nanoparticles

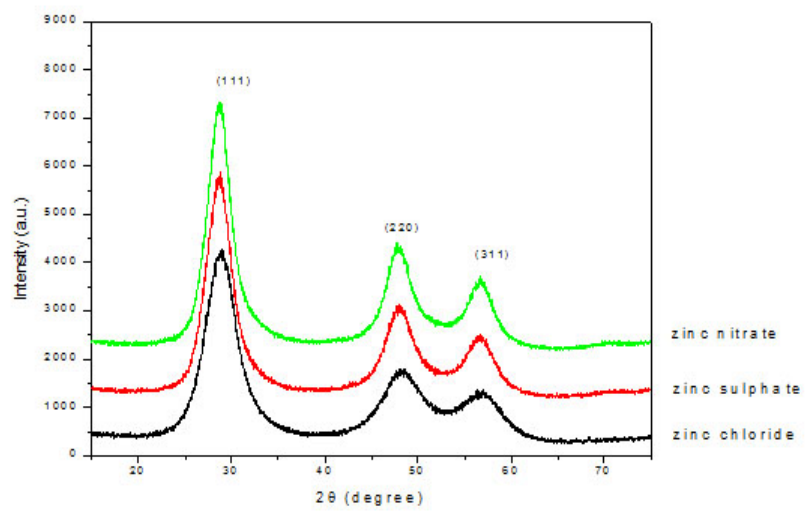

Fig. 1. XRD pattern of ZnTe samples synthesized by using aqueous solution of various precursors.

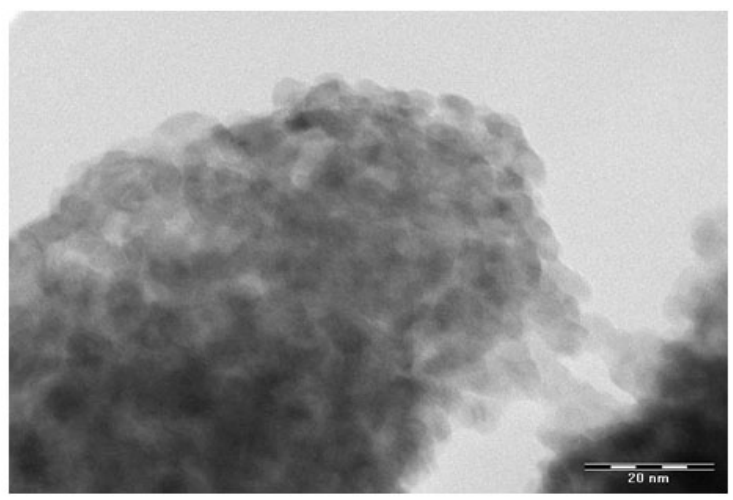

Fig. 3. Transmission Electron Microscopy (TEM) image of ZnTe sample synthesized from aqueous solution of $\mathrm{ZnSO}_{4}$. solution onto carbon coated copper grid and immediately the solvent was evaporated. By utilizing the technique of SAED, the crystalline orientation for specific nanoparticle can be characterized.

\section{Results and Discussion}

The prepared ZnTe nanoparticles were subjected to XRD, TEM and SAED studies for characterization. Their results are presented below:

a. Influence of source compound of zinc on the structure and size of the ZnTe nanocrystallites: The XRD patterns of ZnTe samples synthesized using different zinc source and concentration of $10 \mathrm{mM}$ at room temperature are given in the (Fig. 1). The XRD pattern exhibited three diffraction peaks indexed as (111), (220) and (311). These peaks matched well with those of bulk ZnTe but were comparatively wider than that of bulk due to finite and smaller crystalline size. Since no other characteristics peak were seen in these three different zinc sources, it was concluded that $\mathrm{ZnTe}$ synthesized from $\mathrm{ZnCl}_{2}, \mathrm{ZnSO}_{4}$ and $\mathrm{Zn}\left(\mathrm{NO}_{3}\right)_{2}$ were cubic in structure.

b. Influence of dilution on the structure and size of the $\mathrm{ZnTe}$ samples: Similarly, influence of dilution on ZnTe samples were studied by taking three different concentrations of $\mathrm{ZnSO}_{4}$ as 5, 10 and $20 \mathrm{mM}$. The XRD patterns of those $\mathrm{ZnTe}$ samples of three variation concentration were also cubic crystalline structures, which were confirmed due to the presence of (111), (220) and (311) peaks (Fig. 2).

Fig. 3 and Fig. 4 show the TEM images and ED pattern of $\mathrm{ZnTe}$ nanoparticle prepared from aqueous solution of $\mathrm{ZnSO}_{4}$ and $\mathrm{ZnCl}_{2}$ of $10 \mathrm{mM}$ concentration, respectively. The $\mathrm{ED}$

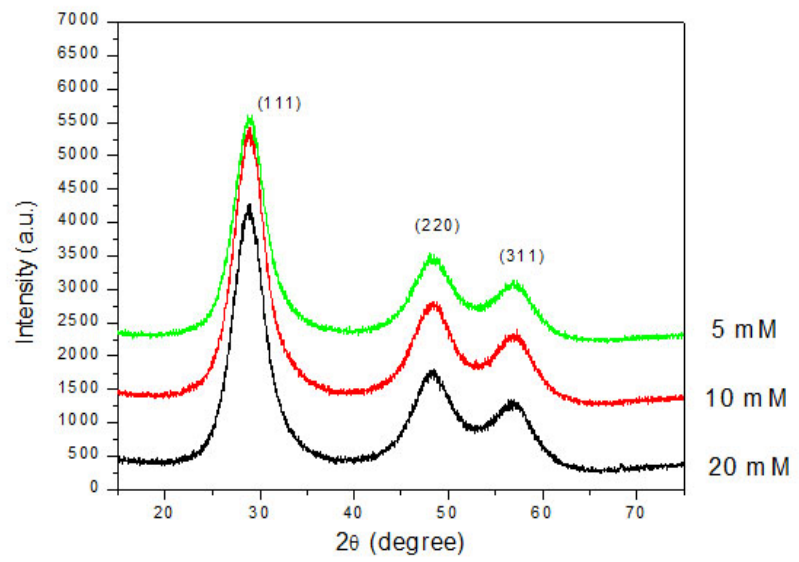

Fig.2. XRD pattern of ZnTe samples synthesized by using solution of various dilutions.

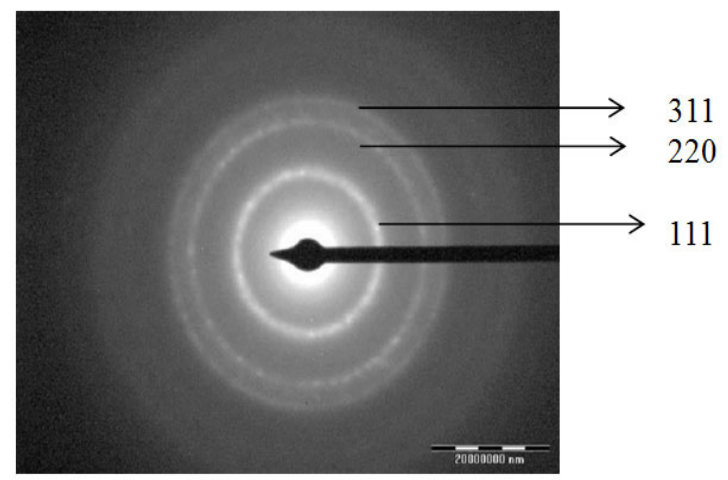

Fig.4. Electron Diffraction (ED) pattern ZnTe sample synthesized from aqueous solution of $\mathrm{ZnCl}$. 
shows rings corresponding to (111), (220) and (311) planes of cubic phase only. The average particle size from TEM image was also estimated to be around $6 \mathrm{~nm}$. ED patterns of other samples also supported the cubic structure of $\mathrm{ZnTe}$ and the particle size calculated form Debye-Scherrer's equations was in consistent with the size estimated from TEM images.

The values of particles size were obtained by using DebyeScherrer's formula for different zinc sources and dilutions. The sizes of particle were found to be varied due to change in source compound of zinc. The particle size of the samples synthesized from $\mathrm{ZnCl}_{2}, \mathrm{Zn}\left(\mathrm{NO}_{3}\right)_{2}$ and $\mathrm{ZnSO}_{4}$ were obtained as $7.5,4.5$ and $6.9 \mathrm{~nm}$, respectively. $\mathrm{Zn}\left(\mathrm{NO}_{3}\right)_{2}$ was found to be the zinc source giving smallest particle size of zinc telluride. The size of particle was found to be increasing as we choose $\mathrm{ZnSO}$ and $\mathrm{ZnCl}_{2}$ as source of zinc. Similarly, $\mathrm{ZnTe}$ synthesized from $\mathrm{ZnSO}_{4}$ at concentration 5,10 and $20 \mathrm{mM}$ exhibited different particles sizes as 4.5, 6.9 and $7.4 \mathrm{~nm}$, respectively.

The size of the particle was found to be decreasing as the dilution of $\mathrm{ZnSO}$ was increased. The size of nanoparticles increased gradually with increase in concentration of $\mathrm{ZnSO}_{4}$ solution as shown in Fig. 5. It gives the conclusion that we can synthesize the desired small size particle by varying the zinc source and increasing the dilution of the $\mathrm{ZnSO}_{4}$.

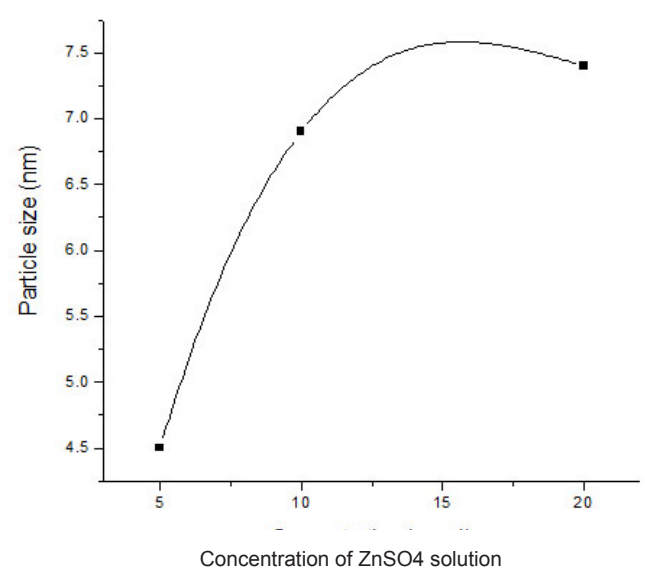

Fig. 5. Plot of particle size of ZnTe nanoparticle versus concentration of $\mathrm{ZnSO}_{4}$ solution.

\section{Conclusion}

ZnTe nanoparticles have been prepared using wet chemical synthesis method and were characterized by XRD, TEM and SAED. The crystallite sizes of the prepared nanoparticle were determined by Debye-Scherrer's equation and it was found about $6 \mathrm{~nm}$. The results of the XRD showed that the average particle size of $\mathrm{ZnTe}$ particles increases with increasing the concentration of $\mathrm{ZnSO}_{4}$. XRD and SAED patterns confirmed the cubic crystalline structure of $\mathrm{ZnTe}$.

ACKNOWLEDGMENTS. Authors are thankful to School of Materials Science and Technology, Indian Institute of Technology (IIT), Banaras Hindu University for XRD data and Consortium for Scientific Research (CSR), Indore, India for TEM images and ED patterns.

\section{References}

Dwivedi, D. K., Dayashankar, and M. Dubey. 2009. Synthesis, characterization and electrical properties of $\mathrm{ZnTe}$ nanoparticles. Journal of Ovonic Research 5(2):35-41.
Ersching, K., F. L. Faita, C. E. M. Campos, T. A. Grandi, and P. S. Pizani. 2010. Ageing effect on mechanically alloyed $\mathrm{ZnTe}$ nanocrystals. Journal of Alloys and Compounds 493:294-298.

Feng, X., K. Singh, S. Bhavanam, V. Palekis, L. D. Morel, and C. Ferekides. 2013. Preparation and characterization of $\mathrm{ZnTe}$ as an interlayer for CdS/CdTe substrate thin film solar cells on flexible substrates. Thin Solid Films 535:202-205.

Hossain, M. S., R. Islam, and K. A. Khan. 2008. Structural, elemental compositions and optical properties of $\mathrm{ZnTe}: \mathrm{V}$ thin films. Chalcogenides Letters 5(1):1-9.

Jiao, S., Q. Shen, I. Mora-Sero, J. Wang, Z. Pan, K. Zhao, Y. Kuga, $\mathrm{X}$. Zhong, and J. Bisquert. 2015. Band engineering in core/shell $\mathrm{ZnTe} / \mathrm{CdSe}$ for photovoltage and efficiency enhancement in exciplex quantum dot sensitized solar cells. ACSNANO 9(1):908915.

Kim, J. D., J. W. Kim, J. E. Kim, and K. K. Koo. 2011. Formation of 1-D ZnTe nanocrystals by aerosol-assisted spray pyrolysis. Korean Journal of Chemical Engineering 28(4):1120-1125.

Lincheneau, C., M. Amelia, M. Oszajca, A. Boccia, F. D’Orazi, M. Madrigale, R. Zanoni, R. Mazzaro, L. Ortolani, V. Morandi, S. Silvi, K. Szacilowski, and A. Credi. 2014. Synthesis and properties of $\mathrm{ZnTe}$ and $\mathrm{ZnTe} / \mathrm{ZnS}$ core/shell semiconductor nanocrystals. Journal of Materials Chemistry C 2:2877-2886.

Liu, Z., G. Chen, B. Liang, G. Yu, H. Huang, D. Chen, and G. Shen. 2013. Fabrication of high-quality ZnTe nanowires toward highperformance rigid/flexible visible-light photodetectors. Optics Express 21(6):7799-7810.

Loffler, T., T. Hahn, M. Thomson, F. Jacob, and H. G. Roskos. 2005. Large-area electro-optic ZnTe terahertz emitters. Optic Express 13(14):5353-5362.

Mntungwa, N., V. S. R. Puilabhotla, and N. Revaprasadu. 2012. The synthesis of core-shell metal-semiconductor nanomaterials. Materials Letters 81:108-111.

Mohd, S., S. Aarya, R. Singh, M. Arora, G. Bhagavannarayana, and T. D. Senguttuvan. 2012. Synthesis of ZnTe nanoparticles by microwave irradiation technique and their characterization. Nanoscience Nanotechnology Letter 4:405-408.

Orii, T., M. Hirasawa, and T. Seto. 2007. Effect of in situ annealing on structure and optical properties of ZnTe nanoparticles produced by pulsed laser ablation. Journal of Physics 59:716-719.

Promnopas, W., T. Thongtem, and S. Thongtem. 2014. ZnTe Semiconductor-polymer gel composited electrolyte for conversion of solar energy. Journal of Nanomaterials (http:// dx.doi.org/10.1155/2014/529629).

Sharma, D. C., S. Srivastava, Y. K. Vijay, and Y. K. Sharma. 2013. Preparation and optical properties of $\mathrm{ZnTe} / \mathrm{ZnTe}$ :Cr. Advanced Materials Letters 4(1):68-70.

Shaygan, M., T. Gemming, V. Bezugly, G. Cuniberti, J.-S. Lee, and M. Meyyappan. 2014. In situ observation of melting behavior of ZnTe nanowires. Journal of Physical Chemistry 118:15061-15067.

Xia, Y., P. Yang, Y. Sun, W. Yiying, B. Mayers, B. Gates, Y. Yin, F. Kim, and H. Yan. 2003. One-Dimensional nanostructures: synthesis, characterization and applications. Advanced Materials 15(5):353389 . 